\title{
Race, Gender and Adiposity in Children
}

JA Smith, DK Francis, TS Ferguson

Obesity is now considered a global epidemic with adverse effects on health and well-being (1). Over the last four decades, both developed and developing countries have seen increased prevalence of overweight and obesity in infancy, childhood and adulthood (2). Global projections suggest that by 2030 over three billion adults may be overweight or obese (1). Additionally, the worldwide prevalence of childhood overweight and obesity is projected to increase with an expected 60 million children being affected by the year 2020 (3). Obesity in childhood tracks into youth and adulthood, thus making childhood obesity a major public health concern (4).

The causes of obesity are multi-factorial and research conducted by scientists around the world have indicated that there are ethnic, gender, societal and cultural underpinnings driving this epidemic $(5,6)$. In order to determine precisely which of these factors has the greatest influence on the prevalence of obesity in children, we will need to conduct large multi-ethnic longitudinal studies from early infancy. Until such studies are conducted, however, much can be learnt from large cross-sectional studies with comparisons of putative obesogenic factors. Questions to be considered include whether race or gender differences in childhood obesity are influenced by genetic factors being displayed in an 'obesogenic' environment or whether there are hormonal and physiological changes which account for these differences.

In this issue of the Journal, Goon and colleagues report on a study which assessed the differences in the body fat percentage, estimated from skinfold thickness measurements, in urban South African children, 9-13 years old, and compared gender and racial differences in adiposity (7). Their main findings were that Black-African children had higher percentage body fat than their White-African counterparts, and that girls had significantly higher values than males in all age groups. These findings support the notion that both ethnicity and gender have significant influences on adiposity, and adds to the body of research that show differences in adiposity between these groups in paediatric populations (6, 8).

From: Tropical Medicine Research Institute (Epidemiology Research Unit), The University of the West Indies, Kingston 7, Jamaica.

Correspondence: Dr T Ferguson, Epidemiology Research Unit, Tropical Medicine Research Institute, The University of the West Indies, Kingston 7 , Jamaica. E-mail: trevor.ferguson02@uwimona.edu.jm
Racial and ethnic differences in obesity and adiposity have also been demonstrated in paediatric populations in the United States of America (USA), where non-Hispanic black and Hispanic groups report higher prevalence of overweight and obesity when compared with other racial and ethnic groups (8). In a study among children aged 8-19 years, there were significant differences in both body mass index (BMI) and per cent body fat when comparing non-Hispanic whites to non-Hispanic black boys and girls (9). In non-Hispanic black girls, BMI values were higher than non-Hispanic whites, however, this did not correspond to the same differences when the per cent body fat was measured using the dual-energy X-ray absorptiometry (DEXA) technique. The non-Hispanic black girls had lower per cent body fat values than their non-Hispanic white counterparts (9). In boys, non-Hispanic blacks had significantly lower per cent body fat and higher fat-free mass than their non-Hispanic white counterparts. This difference in results for the boys may in part be due to the greater accuracy of the DEXA measurement for assessing body composition and highlights that BMI alone may sometimes misclassify adiposity.

Gender differences in body fat percentage were also reported in the study by Goon and colleagues, where in both ethnic groups, girls had higher body fat percentage than boys (7). Similar findings were observed in development of the body fat percentage curves for children in the USA as reported by Ogden and colleagues (10). When the National Health and Nutrition Examination Survey (NHANES) data were analysed, they found that girls had higher body fat percentages than boys, at all age groups from 8-19 years (10). A significant decrease in body fat was observed in boys as they entered puberty in the NHANES study, which continued until the late adolescence (10). This, however, was not seen in girls where there was a gradual increase in percentage body fat as they got older (10).

Residence in an urban environment may also have a significant influence on adiposity, as urban children may have higher dietary intake of high fat and high caloric foods, and increased consumption of foods away from home (1113). In the Caribbean region, there have been reported differences in the prevalence of obesity between urban and rural children and between males and females. One study conducted in an older adolescent population (15-19 years old) reported that the prevalence of both overweight and obesity combined was $23 \%$ higher in the urban compared to 
the rural Jamaican population (14). In another study among children 6-10 years old in Jamaica, Blake-Scarlett and colleagues reported that the prevalence of obesity among children in urban public schools was more than twice that seen among children in rural public schools (15). The odds of overweight and obesity were also significantly different between boys and girls, with overweight and obesity being 1.5 and 1.4 times higher in girls than boys (15).

Other environmental factors such as physical activity and diet also play important roles in the development of overweight and obesity. In a study comparing AfroCaribbean children to their White Canadian counterpart, physical activity was found to be associated with increased overweight and obesity among both ethnic groups (16). Additionally, sweetened beverage consumption was found to increase the odds of both central obesity and increased BMI among Jamaican youth 15-19 years old (17).

A plethora of unanswered questions remain with regards to the mechanisms underlying the racial and gender differences in overweight and obesity in the paediatric population. Given the global impact of this epidemic and the projected increases in the burden of obesity and obesityrelated diseases, there is an urgent need to understand these mechanisms. The development of culturally appropriate interventions to reduce the prevalence of obesity, which take into consideration the nuances of race and gender, as well and parental and household influences is also needed. The impetus is therefore placed on the governments to include in their health agenda solutions which include a multi-level approach to obesity prevention.

\section{REFERENCES}

1. Kelly T, Yang W, Chen CS, Reynolds K, He J. Global burden of obesity in 2005 and projections to 2030. Int J Obes (Lond) 2008; 32: 1431-7.

2. Malik VS, Willett WC, Hu FB. Global obesity: trends, risk factors and policy implications. Nat Rev Endocrinol 2013; 9: 13-27.

3. de Onis M, Blossner M, Borghi E. Global prevalence and trends of overweight and obesity among preschool children. Am J Clin Nutr 2010; 92: 1257-64. doi: 10.3945/ajcn.2010.29786. Epub 2010 Sep 22.
4. Singh AS, Mulder C, Twisk JWR, Van Mechelen W, Chinapaw MJM. Tracking of childhood overweight into adulthood: a systematic review of the literature. Obesity Reviews 2008; 9: 474-88.

5. Kanter R, Caballero B. Global gender disparities in obesity: a review. Adv Nutr 2012; 3: 491-8.

6. Wang Y. Disparities in pediatric obesity in the United States. Adv Nutr 2011; 2: 23-31.

7. Goon DT, Toriola AL, Shaw BS, Amusa LO, Khoza LB, Shaw I. Body fat percentage of urban South African children: implications for health and fitness. West Indian Med J 2013; 62: 582- 8.

8. Skinner AC, Skelton JA. Prevalence and trends in obesity and severe obesity among children in the United States, 1999-2012. JAMA Pediatr 2014. doi: 10.1001/jamapediatrics.2014.21. Epub ahead of print.

9. Flegal KM, Ogden CL, Yanovski JA, Freedman DS, Shepherd JA, Graubard BI et al. High adiposity and high body mass index-for-age in US children and adolescents overall and by race-ethnic group. Am J Clin Nutr 2010; 91: 1020-6.

10. Ogden CL, Li Y, Freedman DS, Borrud LG, Flegal KM. Smoothed percentage body fat percentiles for U.S. children and adolescents, 1999-2004. Natl Health Stat Report 2011; 9: 1-7.

11. Basu S, McKee M, Galea G, Stuckler D. Relationship of soft drink consumption to global overweight, obesity, and diabetes: a crossnational analysis of 75 countries. Am J Public Health 2013; 103: 20717.

12. Popkin BM. Global nutrition dynamics: the world is shifting rapidly toward a diet linked with noncommunicable diseases. Am J Clin Nutr 2006; 84: 289-98.

13. Lobstein T, Baur L, Uauy R. Obesity in children and young people: a crisis in public health. Obes Rev 2004; 5 (Suppl 1): 4-104.

14. Wilks R, Younger N, McFarlane S, Francis D, Van Den Broeck J. Jamaican Youth Risk and Resiliency Behaviour Survey 2006, community-based survey on risk and resiliency behaviours of 15-19 year olds. Kingston: University of the West Indies, USAID; 2007.

15. Blake-Scarlett BE, Younger N, McKenzie CA, Van Den Broeck J, Powell C, Edwards S et al. Prevalence of overweight and obesity among children six to ten years of age in the North-East Health Region of Jamaica. West Indian Med J 2013; 62: 171-6.

16. Dubois L, Francis D, Burnier D, Tatone-Tokuda F, Girard M, GordonStrachan G et al. Household food insecurity and childhood overweight in Jamaica and Quebec: a gender-based analysis. BMC Public Health 2011; 11: 199. doi: 10.1186/1471-2458-11-199.

17. Francis DK, Van den Broeck J, Younger N, McFarlane S, Rudder K, Gordon-Strachan G et al. Fast-food and sweetened beverage consumption: association with overweight and high waist circumference in adolescents. Public Health Nutrition 2009; 12: 1106-14. 